\title{
The population genetic structure of Biomphalaria choanomphala in Lake Victoria, East Africa: implications for schistosomiasis transmission
}

\author{
Claire J Standley ${ }^{1,2,4^{*}}$, Sara L Goodacre ${ }^{1}$, Christopher M Wade ${ }^{1}$ and J Russell Stothard ${ }^{3}$
}

\begin{abstract}
Background: The freshwater snail Biomphalaria acts as the intermediate host of Schistosoma mansoni, a globally important human parasite. Understanding the population structure of intermediate host species can elucidate transmission dynamics and assist in developing appropriate control methods.

Methods: We examined levels of population genetic structure and diversity in 29 populations of Biomphalaria choanomphala collected around the shoreline of Lake Victoria in Uganda, Kenya and Tanzania, where S. mansoni is hyper-endemic. Molecular markers were utilized to estimate the degree to which snail populations are genetically differentiated from one another.

Results: High levels of snail genetic diversity were found coupled with evidence of geographically-determined population structure but low levels of local inbreeding. The data are consistent with an effect of schistosome infection on population structure of intermediate host snails, but other factors, such as habitat and historical demographic changes, could also be important determinants of the degree of population genetic structure in Biomphalaria choanomphala.

Conclusions: The low stratification of populations and high genetic diversity indicates potentially less local compatibility with intermediate snail populations than previously theorized, and highlights the importance of coordinated parasite control strategies across the region.
\end{abstract}

Keywords: Biomphalaria choanomphala, Schistosoma mansoni, Population structure, Population genetics

\section{Background}

Historically, the nature and dynamics of host-parasite relationships has attracted much scientific attention. Parasites of human populations are an area of particular research interest, given the medical interest in controlling their transmission. As such, the genetic diversity and population structure of hermaphroditic Biomphalaria freshwater snails of the family Planorbidae, which are the obligatory intermediate hosts of the globally important parasitic trematode of humans, Schistosoma mansoni, have been the subject of considerable study.

It is known that increased genetic diversity of the host Biomphalaria population reduces the overall parasite

\footnotetext{
* Correspondence: claire.standley@gmail.com

'School of Life Sciences, University of Nottingham, Nottingham NG7 2RD, UK ${ }^{2}$ Department of Zoology, Wolfson Wellcome Biomedical Laboratory, Natural History Museum, Cromwell Road, London SW7 5BD, UK

Full list of author information is available at the end of the article
}

transmission rate whereas reduced host genetic diversity appears to benefit $S$. mansoni through an overall increase in transmission rate [1-5]. It has also been shown that schistosome infection in Biomphalaria reduces snail fitness, but resistance to infection is itself also associated with reduced offspring production, as often seen in other planorbids [6]. As such, it has been predicted that the natural Biomphalaria population structure would result in a tightly coupled system whereby parasites and snails co-adapt, resulting in localized compatibility and comparable population structures, but also driving local high diversity [7]. Of course, parasites other than Schistosoma could equally be implicated in driving diversity in such a system, as Biomphalaria are known to serve as intermediate hosts for a number of nematode and trematode worms $[8,9]$. 
Parasites such as S. mansoni are, however, not the only external factor known to influence their host. Selection driven by environmental factors, such as seasonality or habitat type, has also been shown to affect freshwater snail population differentiation [10-12]. There may also be anthropogenic influences, for example, removal of snails as part of disease control programs [13].

B. glabrata and B. pfeifferi are considered two of the most important intermediate host snail species of S. mansoni in the New and Old World, respectively, and most previous work on snail-schistosome population structure has focused on these species [14]. There are, however, other regions of the world where intestinal schistosomiasis is highly endemic, yet transmitted by other Biomphalaria species [15], and fewer studies have focused on these intermediate hosts. In this study we investigate the genetic diversity and population structure of Biomphalaria choanomphala from Lake Victoria, an important lacustrine environment in East Africa, and a well-known regional hot spot for transmission of S. mansoni [16-19]. The aim of the study is to determine the population structure of Biomphalaria choanomphala in this hyper-endemic region for schistosomiasis, at a large scale, to better understand factors that may contribute to parasite transmission.

\section{Methods}

The degree of population differentiation of Biomphalaria choanomphala in Lake Victoria was inferred from genetic variation in two mitochondrial genes (cytochrome oxidase sub-unit one (COI) and 16S ribosomal RNA (16S)), and four bi-parentally inherited nuclear microsatellite loci.

\section{Sampling methodology and population selection}

Snails were collected from 29 sites around the perimeter of Lake Victoria, using hand held scoops (Figure 1). Sampling was semi-quantified, with two collectors each surveying a $50 \mathrm{~m}$ length of shoreline for approximately 20 minutes and collecting all Biomphalaria found. Sites were selected to ensure an even geographical spread along the lakeshore, in all three countries and in both marsh and lake habitats; five localities were specifically included because they incorporated both habitat types in close proximity. All sites showed signs of human activity near the shoreline. In order to compare sites of similar population density, all sites selected had a high abundance of Biomphalaria, defined as 30 or more individuals collected, which accounted for the paucity of sites along the eastern shoreline of the lake in Tanzania, where Biomphalaria densities were generally low.

Snails were putatively identified as B. choanomphala or B. sudanica, based on shell morphology, as these are the species thought primarily to inhabit Lake Victoria [15]. However, recent taxonomic work has suggested that all the Biomphalaria in Lake Victoria can be considered a single species of which ecophenotypy of shell form gives rise to the previously considered taxonomic distinctions [20], and thus for the purposes of this study, individuals were simply classed as being one of the two morphotypes of $B$. choanomphala.

All collected snails (in total $>30$ per site, given the site selection criteria) were exposed, as a group, to sunlight for 2-4 hours to check for infection with Schistosoma mansoni or other parasite cercariae [21]. A random sample of snails was examined in this way on subsequent days, to ensure maximum reliability of infection testing. After shedding, snails were placed in glass tubes containing $95 \%$ ethanol solution.

\section{DNA extraction, amplification and sequencing}

Genomic DNA was extracted from between 10 and 12 individuals from each of the selected 29 populations, using a standard CTAB extraction [22] with a final re-suspension in pure water. The mitochondrial cytochrome oxidase sub-unit one (COI) gene and the mitochondrial $16 \mathrm{~S}$ subunit of the ribosomal RNA gene were amplified using the Folmer 'universal' primers [23] and modified 16ar and $16 \mathrm{br}$ primers [24], respectively. The four microsatellite loci were Bpf1, Bpf2, Bpf3 and Bpf10 [25] - all nine of the primers described in referenced paper were tested, but the above four were the only ones which amplified successfully and were polymorphic in the Lake Victoria Biomphalaria choanomphala under examination here. Mitochondrial (COI and 16S) amplifications were carried out in $25 \mu \mathrm{l}$ total volume, with $2.5 \mu \mathrm{l} \mathrm{MgCl}_{2}$ (20 mM concentration), $2.5 \mu \mathrm{l} 5 \times$ buffer, $2.5 \mu \mathrm{l}$ premixed dNTPs (20 mM concentration), $1 \mu \mathrm{l}$ each of forward and reverse primer (10 pmol concentration) and one unit of TAQ per reaction. Microsatellite reactions were amplified in $12.5 \mu \mathrm{l}$ total volume, with half of the volumes stated above, and with forward primer concentration of $50 \mathrm{pmol}$ and reverse (fluorescently labeled) primer concentration of $20 \mathrm{pmol}$. Cycling conditions in all cases followed published methods [23-25].

Positively amplified products were purified using Millipore PCR $_{96}$ Cleanup kits on a vacuum manifold (Millipore, Billerica, USA) as per manufacturer's instructions, using pure water for washing and re-suspension. Product concentration was quantified on a Nanodrop ND-1000 Spectrophotometer (Nanodrop Technologies Inc., Willington, USA), and sequencing reactions were performed on mitochondrial purified PCR products using an Applied Biosystems Big Dye Kit (version 1.1) and run on an Applied Biosystems 3730 DNA Analyzer (Applied Biosystems, Carlsbad, USA). Microsatellites were diluted 1:10 in HiDiformamide (Applied Biosystems, as above) and analyzed using an ABI3730 automated sequencer, using a GeneScan 500 LIZ size standard (both Applied Biosystems, as above). 


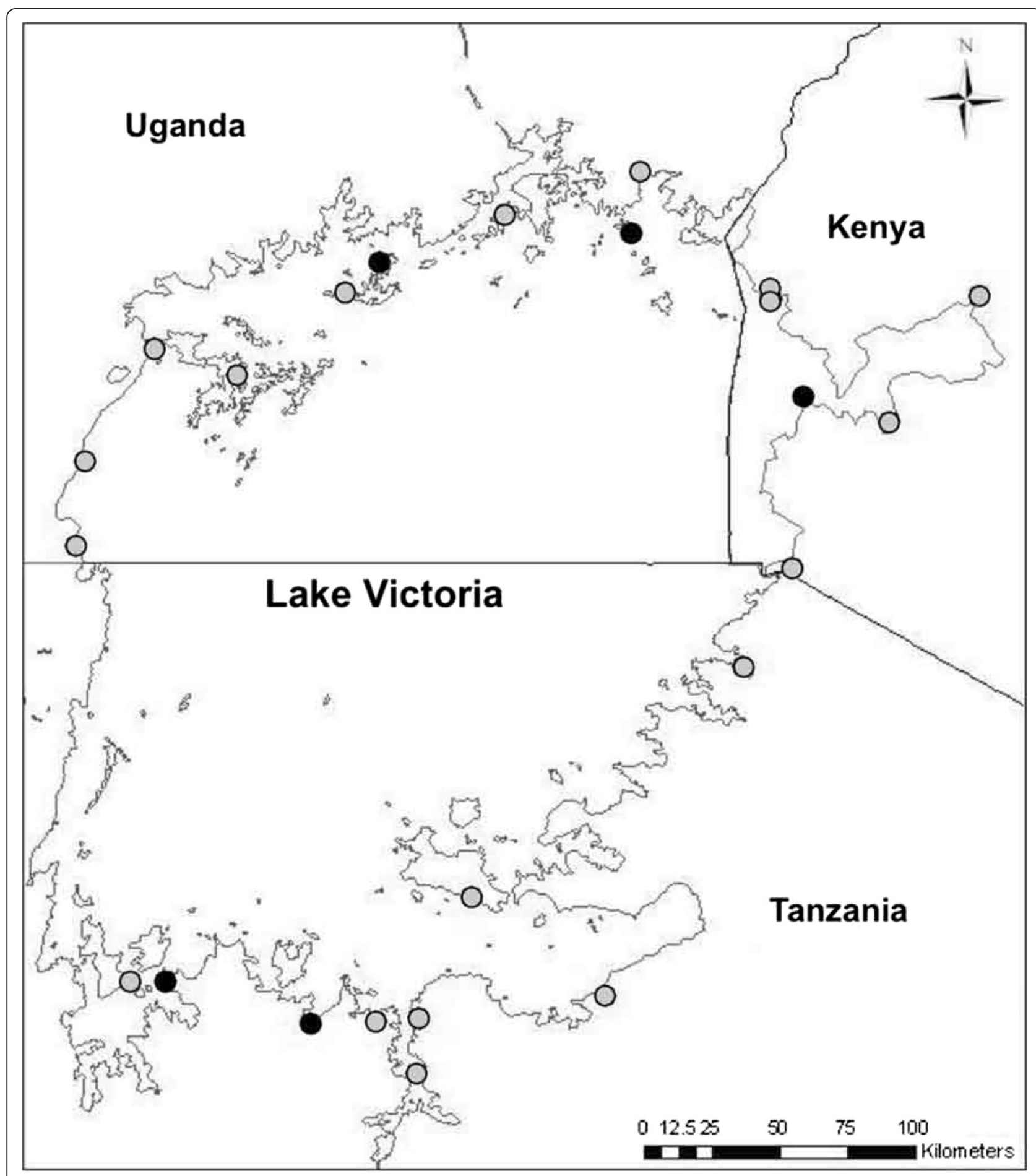

Figure 1 Map of the 29 study sites around Lake Victoria. "Single habitat" sites (marked by grey circle) denote an area with a single habitat (lake or marsh); "Joint habitat" sites (marked by black circle) indicate localities where a marsh and lake habitat were found together, and snails collected separately from each.

\section{Population analyses}

The overall framework of the population genetics analyses were designed to examine the population structure, diversity, demography, phylogeography and spatial correlations of the B. choanomphala populations surveyed from Lake Victoria [2].

$\mathrm{COI}$ and $16 \mathrm{~S}$ mitochondrial sequences were aligned using MUSCLE on the web (http://www.ebi.ac.uk/Tools/ 
$\mathrm{msa} / \mathrm{muscle} /$ ) and edited visually in MacClade $\mathrm{v} 4$ [26]. The aligned sequences were then compared and reduced to unique haplotypes, and the proportion of each haplotype per population was recorded. The $16 \mathrm{~S}$ data contained many gap-rich regions, for which it was impossible to be assured of homology; any region with a gap was therefore removed from the alignment before calculating genetic distances amongst sequences. There was only one indel region in the COI alignment, of a single codon repeat, in three haplotypes, which was therefore easily alignable and retained for haplotype analysis.

Measures of population differentiation were calculated from mitochondrial sequence data using analysis of molecular variance (AMOVA), F-statistics, mismatch analysis, Tajima and Fu's tests for neutrality and a Mantel z-test for correlation by distance. Each AMOVA was conducted using "country" as the primary grouping, to investigate the level of variation partitioned between each country, versus between populations within each country and within each population. "Country" was deemed to be a potentially important geographical factor given that each country in the region undertakes different levels of schistosomiasis control initiatives, thus potentially influencing the level of parasitism experienced by local snails. All tests were executed in Arlequin v 3.2 [27].

A distance-based, neighbor-joining tree was created in Paup* 4.0 [28] for the unique haplotypes that remained when indels were removed from the alignment from each gene, using the GTR + gamma model of sequence evolution, determined to be the most appropriate model through likelihood testing, also in Paup* 4.0. Medianjoining networks were constructed using Network 4.6 [29] based on the gap-free unique haplotypes.

The number and proportion of private microsatellite alleles per population was calculated using the webbased version of Genepop [30]. Calculations of $\mathrm{F}_{\mathrm{ST}}$ and tests for Hardy-Weinberg equilibrium (through estimation of $\mathrm{F}_{\mathrm{IS}}$ values per population and per locus) and linkage disequilibrium amongst loci were also done using Genepop. The loci were also tested for evidence of previous bottlenecking events by comparing the allelic diversity against the observed and expected heterozygosity, using the program Bottleneck [31].

\section{Results}

In total, over 300 Biomphalaria choanomphala were analyzed from the selected 29 populations. Both the mitochondrial markers and the microsatellites revealed high levels of genetic variation overall, but also significant population structuring throughout the lake as described below.

\section{Mitochondrial data}

The COI and $16 \mathrm{~S}$ sequences were very genetically variable with 127/308 (CO1) and 181/300(16S) unique haplotypes/ total number of sequences respectively. Haplotypes were not highly divergent (0.002-0.058 pairwise distance for COI haplotypes and 0.000-0.047 for 16S). GenBank accession numbers for these datasets are HM769132-HM769258 for COI and HM768950-HM768980 and HM768982HM769131 for 16S. When unalignable regions with gaps were removed from the analysis of the $16 \mathrm{~S}$ sequences, the number of unique haplotypes was reduced from 181 to 64 . Many common haplotypes were spread throughout the lake, but others were locally restricted and there was high variation in the haplotype richness of the sites: overall, intra-site haplotype diversity estimates varied from 0.200 0.982 for COI and $0.378-1.000$ for $16 \mathrm{~S}$, where zero indicates complete homogeneity and one indicates maximum diversity.

Figure 2 shows the geographical distribution of the five most abundant COI and 16S ("A" and "B" maps in Figure 2, respectively) haplotypes (without removal of indels) per population across Lake Victoria, as compared to the frequency of other shared haplotypes and "private" haplotypes (i.e. haplotypes only observed at one site). The map reveals patterns of higher and lower haplotype sharing versus uniqueness within and between localities and countries; for example, Kenyan sites tended to share haplotypes whereas Ugandan sites, especially those in the central and western regions of the lakeshore, had high proportions of private haplotypes. Maps showing the distribution of all the haplotypes for COI and 16S, plus a full list of haplotype frequencies per site, can be found in the supplementary information (See Additional file 1: Figure S1, Additional file 2: Figure S2, Additional file 3: Table S1 and Additional file 4: Table S2 for COI and $16 \mathrm{~S}$ respectively).

The phylogenetic trees for COI and 16S (Figure 3) were consistent, as would be expected from linked loci, and showed few deep divisions, but several more recent processes of divergence. These supported the hypothesis of geographical structuring, as divergent clades tended to be made up of haplotypes from the same country, or limited to two out of the three countries. The networks for each mitochondrial marker were difficult to analyze visually due to the large number of haplotypes (See Additional file 5: Figure S3 for COI and Additional file 6: Figure S4 for 16S). However there appeared to be evidence of geographical clustering by country; for both markers, the most abundant and geographical widespread haplotype ( $\mathrm{H} 1$ for $\mathrm{COI}$ and $\mathrm{H} 2$ for $16 \mathrm{~S}$; the network software utilized the gap-free dataset) was a central node within each respective network.

The majority of the variation, for both the $\mathrm{COI}$ and the $16 \mathrm{~S}$ data, was explained at the population level based on the analysis of molecular variance (AMOVA), which sought to determine how diversity was partitioned among and between the different sites. For these data, all three levels of structure (intergroup, intragroup and intrapopulation) were statistically significantly differentiated (see Table 1). 


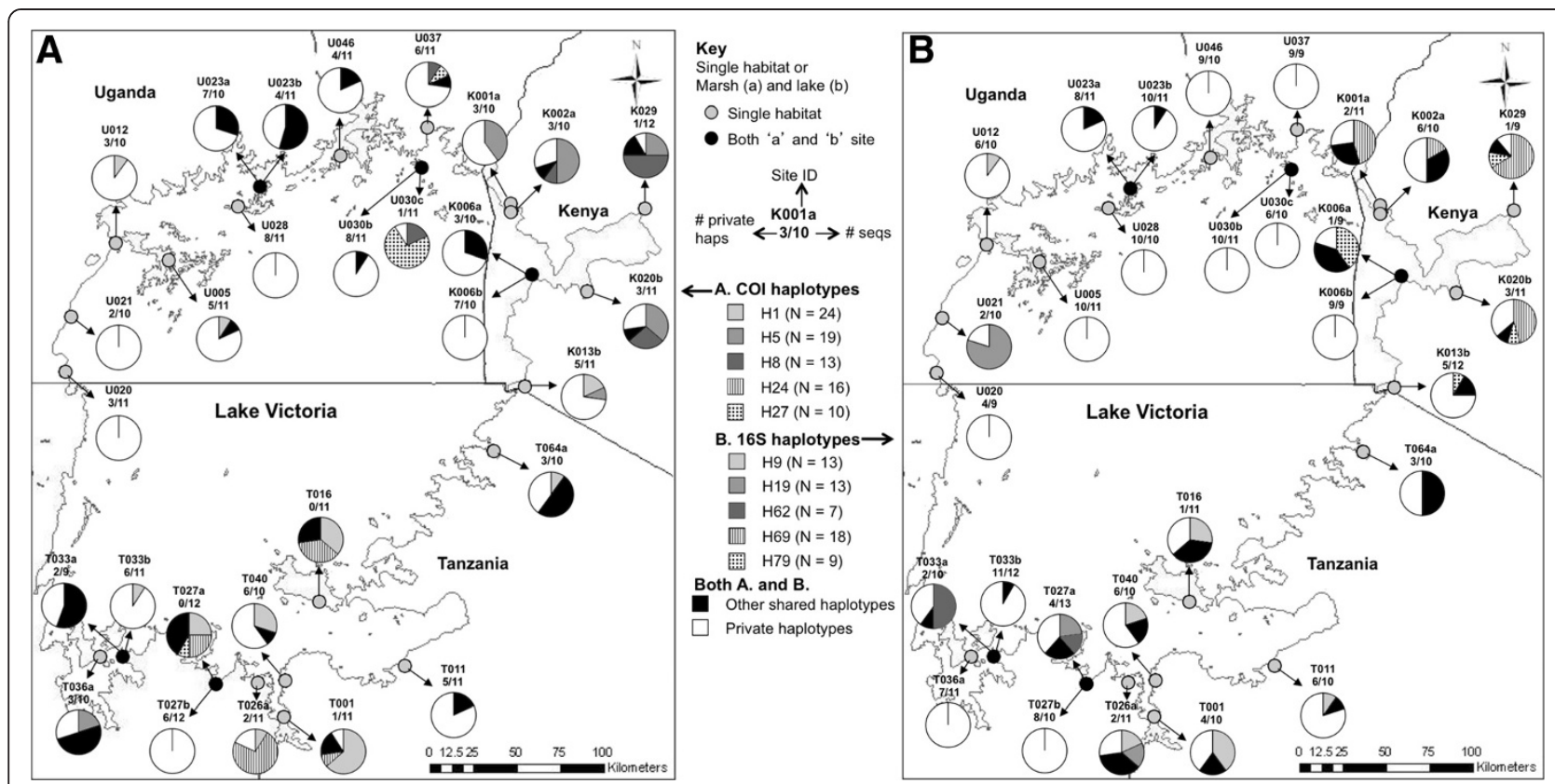

Figure 2 Distribution of abundant, shared and private haplotypes around Lake Victoria study sites. "A" shows data for COI haplotypes; "B" shows data for 165 haplotypes (with gap dataset).

When pair-wise fixation index $\left(\mathrm{F}_{\mathrm{ST}}\right)$ values were calculated between each of the populations in turn, the majority demonstrated significant levels of differentiation, for both types of molecular marker. The range in values was $0.000-0.921$ for COI and 0.000-0.845 for 16S. For the $16 \mathrm{~S}$ data, all but one of the non-significant $\mathrm{F}_{\mathrm{ST}}$ values were between sites in the same country, once again demonstrating geographically defined structuring of the populations for this gene. All but one paired site showed significant differentiation between the populations from lake versus marsh habitat, indicating even small-scale geographical segregation. Full tables of the pairwise $\mathrm{F}_{\mathrm{ST}}$ values and their significance can be found in the supplementary information (See Additional file 7: Tables S3 and Additional file 8: Tables $\mathrm{S} 4$ respectively for COI and $16 \mathrm{~S}$ ).

All of the populations conformed to the assumptions of the neutral hypothesis, as tested for by Tajima's D statistic for the 16S data; one population, T001, deviated significantly ( $\mathrm{p}<0.001)$ from assumptions of normality when the COI data was analyzed. However, this population also had a significant result for the sum of squares mismatch analysis ( $\mathrm{p}<0.001$ ), suggesting that demographic change, such as population expansion, may have biased the neutrality test. No other populations, for either marker, came out as significant in the mismatch analysis.

The relationship with geography was elucidated through the significance of the Mantel z-test for both the COI and $16 \mathrm{~S}$ data ( $\mathrm{p}=0.001$, for both), meaning that the genetic and geographical distances between the populations was positively correlated; in other words, sites closer together were more likely to be genetically similar, even if the composition of distinct haplotypes differed per site (as seen in Figure 3 and Additional file 1: Figure S1). This demonstrated an overall relationship between genetic differentiation and geographic distance, on top of the localized differentiation already described, such as between marsh and lake habitats (Additional file 5: Figure S3 and Additional file 6: Figure S4).

\section{Microsatellite data}

The microsatellite data were tested for departures from Hardy-Weinberg equilibrium (HWE), linkage disequilibrium and for an excess of heterozygosity relative to allelic diversity, which would be consistent with populations having recently passed through a bottleneck.

As with the mitochondrial data, based on an AMOVA, the majority of the variation in microsatellite genotype was explained at the population level; values of differentiation at the intragroup and intrapopulation were both highly significant (explaining $10.55 \%$ and $89.13 \%$ of the total variation observed, respectively: Table 2). Much less variation was explained between country-level groups for the microsatellite data $(0.31 \%)$ than for either of the mitochondrial genes, but instead there was a larger proportion of diversity within populations ( $>89 \%)$. Pairwise $\mathrm{F}_{\mathrm{ST}}$ values ranged from $0.000-0.298$, but fewer values were significant between populations, compared to the mitochondrial data. The full matrix of pairwise $\mathrm{F}_{\mathrm{ST}}$ values and their significance can be found in the supplementary information (Additional file 9: Table S5). Supporting the $F_{\mathrm{ST}}$ 


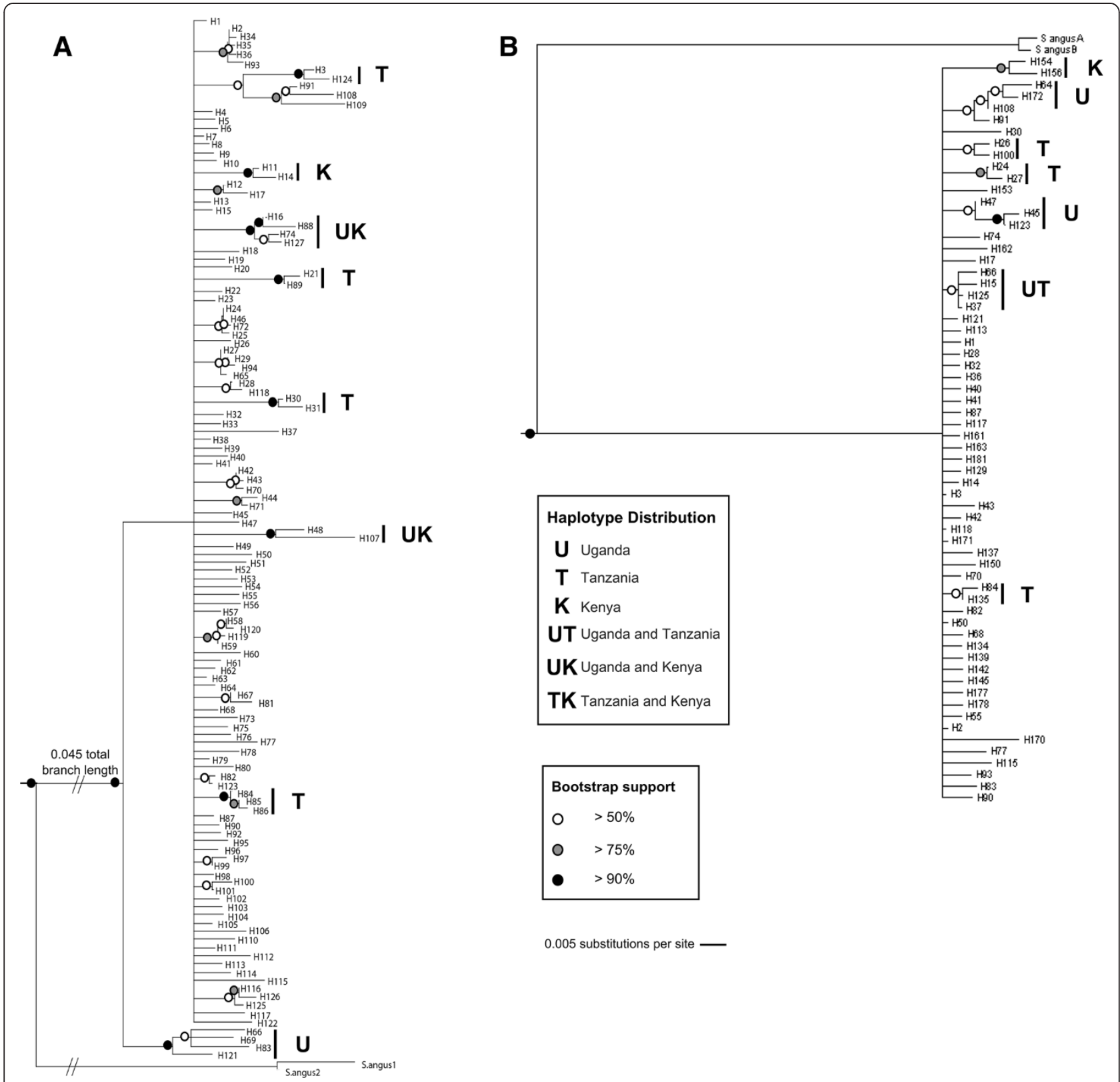

Figure 3 Neighbor-joining trees of $\mathrm{COI}($ "A") and $16 \mathrm{~S}$ (" $\mathrm{B}$ ") data. The level of bootstrap support is indicated by the color of the circle on the node; only support values $>50 \%$ are shown.

values in suggesting low gene flow between populations, 17 out of the 28 populations with microsatellite data had private alleles at one or more loci, and the proportions of private alleles across all populations and alleles was highly significant (Fisher's method, $\mathrm{p}=<0.001$ ). The microsatellite data also supported the mitochondrial evidence for genetic spatial autocorrelation, as the Mantel z-test was significant $(\mathrm{p}=0.017)$.

Intrapopulation tests however showed low levels of inbreeding within populations, based on the calculations of $\mathrm{F}_{\mathrm{IS}}$ values per locus as well as across all loci. $\mathrm{F}_{\mathrm{IS}}$ values, across all loci, per population, ranged from -0.186 to 0.168 (Table 3), with a mean value across all populations of 0.019 , indicative of random mating. More generally, all populations conformed to the assumptions of HWE in terms of observed and expected heterozygosity, supporting the hypothesis that there are low levels of selfing.

There was also no evidence for linkage disequilibrium between the loci, suggesting that the alleles considered are not closely associated in the genome and are mixing randomly during gamete production. Four populations (K013b, T001, T027b and U028), when tested for 
Table 1 Analysis of molecular variance (AMOVA) results for COI and $16 \mathrm{~S}$ data

\begin{tabular}{|c|c|c|c|c|c|c|}
\hline & Source of variation & Degrees of freedom & Sum of squares & $\begin{array}{l}\text { Variance } \\
\text { components }\end{array}$ & $\begin{array}{l}\text { Percentage } \\
\text { of variation }\end{array}$ & p-value \\
\hline \multirow{4}{*}{$\mathrm{COI}$ sequences } & Among countries & 2 & 173.35 & 0.6646 & 12.75 & $<0.0001$ \\
\hline & Among populations, within countries & 26 & 512.68 & 1.5774 & 30.26 & $<0.0001$ \\
\hline & Within populations & 279 & 829.10 & 2.9717 & 57.00 & $<0.0001$ \\
\hline & Total & 307 & 1515.12 & 5.2137 & 100.00 & \\
\hline \multirow{4}{*}{$16 \mathrm{~S}$ sequences } & Among countries & 2 & 155.88 & 0.5893 & 10.00 & $<0.001$ \\
\hline & Among populations, within countries & 26 & 524.77 & 1.5935 & 27.04 & $<0.0001$ \\
\hline & Within populations & 271 & 1005.55 & 3.7105 & 62.96 & $<0.0001$ \\
\hline & Total & 299 & 1686.20 & 5.8933 & 100.00 & \\
\hline
\end{tabular}

evidence of a past bottleneck, showed heterozygote excess ( $p=0.031$ for all four), but this value was not significant once the Bonferroni correction for multiple tests was applied.

\section{Discussion \\ Population structure of Biomphalaria choanomphala in Lake Victoria}

The populations studied here were characterized by high intrapopulation diversity as well as high levels of population structure, with low levels of gene flow as inferred from molecular data and negligible inbreeding. High diversity is consistent with what would be expected if parasitism were strongly influencing population structure [3,7], and the low $\mathrm{F}_{\mathrm{IS}}$ values and apparent random mating observed here further supports this hypothesis. The snails collected for this research were examined for infection with schistosomes and other parasites in the field as part of a different study; however, without more accurate and consistent methods such as molecular probes [32] for the detection of infected snails (and indeed, infection with potentially more than one parasite species [33]) and infected snail populations, it is difficult to determine whether parasitism is indeed a key driver of population structure in this system. Similarly, future studies should seek to use genetic markers which are known to correlate to parasite resistance or susceptibility, which were not available when this study was conducted, but have since been identified in several studies $[34,35]$. Even so, the challenges of modifying markers for use on field populations of less well-studied African Biomphalaria remain.

We would also expect parasite populations to adapt to local snails, thus mirroring to some extent their population structure. We used a Mantel test [36] to compare the population structure of $B$. choanomphala from the six sites from which there were published data on schistosome population structure [19], and found no correlation. Notwithstanding the limitation of the small number of sites, this conforms to other studies where parasite populations were much less differentiated than those of the intermediate host, suggesting local compatibility in this context is being overshadowed by other factors such as high parasite migration [36,37]. Definitive host migration has been put forward as a factor that might homogenize parasite populations across a wide area, and this is compatible with the Lake Victoria context, where human populations are known to move widely throughout the region [18].

Role of other factors influencing population structure Given the possibility of parasitism as a driver for population structure in Lake Victoria snail populations, it is important to consider what other factors might be influential in this system, and particularly how these differ from previous studies of Biomphalaria in other settings. Such considerations link back to parasitism, and particularly control of schistosomiasis in human populations, in terms of gaining a better understanding of drivers for distribution and abundance of host snails under different conditions. Studies of

Table 2 Analysis of molecular variance (AMOVA) results for microsatellite data

\begin{tabular}{|c|c|c|c|c|c|c|}
\hline & Source of variation & Degrees of freedom & Sum of squares & Variance components & $\begin{array}{l}\text { Percentage } \\
\text { of variation }\end{array}$ & $p$-value \\
\hline \multirow{4}{*}{ Microsatellite data } & Among countries & 2 & 9.51 & 0.0057 & 0.31 & 0.237 \\
\hline & $\begin{array}{l}\text { Among populations, } \\
\text { within countries }\end{array}$ & 23 & 88.36 & 0.1900 & 10.55 & $<0.0001$ \\
\hline & Within populations & 286 & 459.05 & 1.6051 & 89.13 & $<0.0001$ \\
\hline & Total & 311 & 556.93 & 1.8008 & 99.99 & \\
\hline
\end{tabular}


Table 3 Diversity estimates per site for COI, $16 \mathrm{~S}$ and microsatellite data

\begin{tabular}{|c|c|c|c|c|c|c|c|c|c|}
\hline \multirow[t]{2}{*}{ Site } & \multicolumn{2}{|c|}{ General information } & \multicolumn{2}{|l|}{ COI sequences } & \multicolumn{2}{|l|}{$16 \mathrm{~S}$ sequences } & \multicolumn{3}{|c|}{ Microsatellite data } \\
\hline & Shedding & Habitat & Gene diversity & Nucleotide diversity & Gene diversity & $\begin{array}{l}\text { Nucleotide } \\
\text { diversity }\end{array}$ & $\begin{array}{l}\text { Average } \\
\text { gene div. }\end{array}$ & Private alleles & $\mathrm{F}_{\mathrm{IS}}$ \\
\hline K001a & $\mathrm{N}$ & Marsh & 0.836 & 0.005 & 0.746 & 0.005 & 0.885 & 0.000 & -0.010 \\
\hline K002a & $\mathrm{N}$ & Marsh & 0.712 & 0.001 & 0.978 & 0.011 & 0.878 & 0.029 & -0.001 \\
\hline K006а & $\mathrm{N}$ & Marsh & 0.855 & 0.014 & 0.500 & 0.005 & 0.790 & 0.079 & -0.077 \\
\hline K006b & $\mathrm{N}$ & Lake & 0.889 & 0.026 & 1.000 & 0.043 & 0.843 & 0.000 & 0.119 \\
\hline K013b & $\mathrm{N}$ & Lake & 0.909 & 0.014 & 0.879 & 0.012 & 0.710 & 0.139 & 0.025 \\
\hline K020b & $\mathrm{N}$ & Lake & 0.933 & 0.004 & 0.800 & 0.006 & 0.825 & 0.000 & 0.083 \\
\hline K029 & $\mathrm{N}$ & Lake & 0.818 & 0.015 & 0.583 & 0.004 & 0.828 & 0.000 & 0.034 \\
\hline T001 & Y & Marsh & 0.978 & 0.017 & 0.867 & 0.017 & 0.754 & 0.016 & -0.186 \\
\hline T011 & $\mathrm{N}$ & Lake & 0.927 & 0.009 & 0.933 & 0.016 & 0.738 & 0.015 & 0.073 \\
\hline T016 & $\mathrm{N}$ & Marsh & 0.964 & 0.016 & 0.727 & 0.008 & 0.743 & 0.000 & -0.077 \\
\hline T026a & $N$ & Marsh & 0.964 & 0.009 & 0.891 & 0.005 & 0.636 & 0.019 & -0.112 \\
\hline T027a & $N$ & Marsh & 0.782 & 0.010 & 0.923 & 0.018 & 0.848 & 0.014 & -0.180 \\
\hline T027b & $N$ & Lake & 0.733 & 0.003 & 0.956 & 0.033 & 0.735 & 0.050 & 0.038 \\
\hline T033a & $\mathrm{N}$ & Marsh & 0.778 & 0.002 & 0.711 & 0.014 & 0.738 & 0.000 & 0.026 \\
\hline T033b & $Y$ & Lake & 0.778 & 0.004 & 1.000 & 0.021 & 0.758 & 0.014 & 0.134 \\
\hline T036a & $N$ & Marsh & 0.618 & 0.008 & 0.818 & 0.016 & 0.744 & 0.013 & 0.092 \\
\hline T040 & $\mathrm{N}$ & Lake & 0.727 & 0.003 & 0.978 & 0.011 & 0.803 & 0.033 & 0.168 \\
\hline T064a & $\mathrm{N}$ & Marsh & 0.491 & 0.002 & 0.889 & 0.022 & 0.783 & 0.000 & 0.112 \\
\hline U005 & $\mathrm{N}$ & Lake & 0.864 & 0.011 & 0.982 & 0.027 & 0.819 & 0.013 & 0.101 \\
\hline U012 & $\mathrm{N}$ & Marsh & 0.639 & 0.010 & 0.911 & 0.020 & 0.845 & 0.000 & 0.058 \\
\hline U020 & $\mathrm{N}$ & Marsh & 0.756 & 0.006 & 0.583 & 0.007 & 0.806 & 0.028 & 0.116 \\
\hline U021 & $\mathrm{N}$ & Marsh & 0.844 & 0.015 & 0.378 & 0.002 & 0.754 & 0.000 & -0.119 \\
\hline U023a & $\mathrm{N}$ & Lake & 0.644 & 0.004 & 0.978 & 0.033 & 0.818 & 0.000 & -0.039 \\
\hline U023b & $Y$ & Marsh & 0.346 & 0.004 & 1.000 & 0.028 & 0.878 & 0.016 & 0.109 \\
\hline U028 & Y & Lake & 0.200 & 0.000 & 1.000 & 0.025 & 0.857 & 0.015 & 0.014 \\
\hline U030b & $N$ & Marsh & 0.982 & 0.016 & 0.982 & 0.028 & 0.877 & 0.000 & -0.104 \\
\hline U030c & $\mathrm{N}$ & Lake & 0.473 & 0.002 & 0.844 & 0.014 & NA & NA & NA \\
\hline U037 & $Y$ & Lake & 0.836 & 0.005 & 0.978 & 0.019 & 0.833 & 0.012 & 0.091 \\
\hline U046 & $N$ & Lake & 0.712 & 0.001 & 1.000 & 0.030 & 0.868 & 0.025 & 0.050 \\
\hline
\end{tabular}

Information on infection status with schistosomes and the habitat type are also given. " $\mathrm{N}$ " stands for "No" and " $\mathrm{Y}$ " represents "Yes". "div."stands for diversity and "FIS" indicates the inbreeding co-efficient.

B. pfeifferi in Madagascar, for example, revealed high levels of interpopulation variation but, in contrast to what we observed here, consistently low levels of intrapopulation genetic differentiation [11]. This was explained as being due to the combination of low levels of migration combined with habitat stochasticity; B. pfeifferi are also known to be frequent in-breeders, which would assist in maintaining a metapopulation with seasonal local extinction events [38].

In contrast, Lake Victoria possesses very different environmental conditions; as a very large, permanent lake, it rarely experiences the kind of environmental perturbations that characterize temporally transient ponds and streams. Such homogeneity of habitat, with associated infrequent extinctions and opportunity for genetic drift, could account for the high levels of intrapopulation diversity that are maintained in Lake Victorian $B$. choanomphala [2]. This applies mainly to the lake habitats; indeed, this study showed significantly lower levels of gene and nucleotide diversity in the marsh habitats. However, in both lake and marsh populations, the tests for bottleneck events were uniformly negative, 
suggesting that sudden demographical events are not overwhelmingly contributing to the patterns of diversity of Lake Victoria Biomphalaria.

\section{Effect on transmission of intestinal schistosomiasis}

Although the low population structure in S. mansoni observed previously in this region counters the hypothesis of highly specialized local parasite compatibility [19] for both host and parasite, certain $B$. choanomphala haplotypes were widespread around the lake. This suggests that, as seen in B. pfeifferi from elsewhere in Africa, there may be a risk of transmissive genotypes becoming widely successful, if there is selection for traits independent of parasite susceptibility [39].

Another factor to consider is human-mediated changes to parasite populations: all three countries bordering Lake Victoria have initiated efforts to control schistosomiasis in human populations through mass treatment campaigns, although these initiatives are not synchronized and differ in their degree of coverage. The low levels of population structuring seen in the parasite [19] are likely a function of high terminal host migration and rapid dispersal of the parasite into novel localities [36,40]; if some populations of S. mansoni experience more intense selection pressure based on frequent mass drug administration campaigns, and given the generally transmissive snail populations, there is a risk that these highly adapted forms of $S$. mansoni will be able to spread rapidly throughout the region. This emphasizes the need for coordinated control strategies, both at the level of human treatment as well as improved water access and sanitation, throughout lakeshore communities in the region.

\section{Conclusions}

In summary, our analysis observed high genetic diversity of $B$ choanomphala snails, yet also high population structuring; the high levels of observed inter- and intrapopulation diversity are consistent with parasitism as an influencing factor, but further investigation is needed, utilizing new tools to detect infection and new markers directly associated with resistance or susceptibility, in order to confirm the role of parasitism in driving high diversity in this system. Moreover, other factors, such as environmental and demographical stability may also contribute to the observed population structure. From a public health perspective, population genetic surveys of intermediate hosts should seek to increase the scale of their focus, as parasite transmission is likely influenced by factors, such as human migration and national treatment campaigns, that act on a national or even regional level. Public health initiatives should take such issues of scale into consideration when designing control strategies.

\section{Additional files}

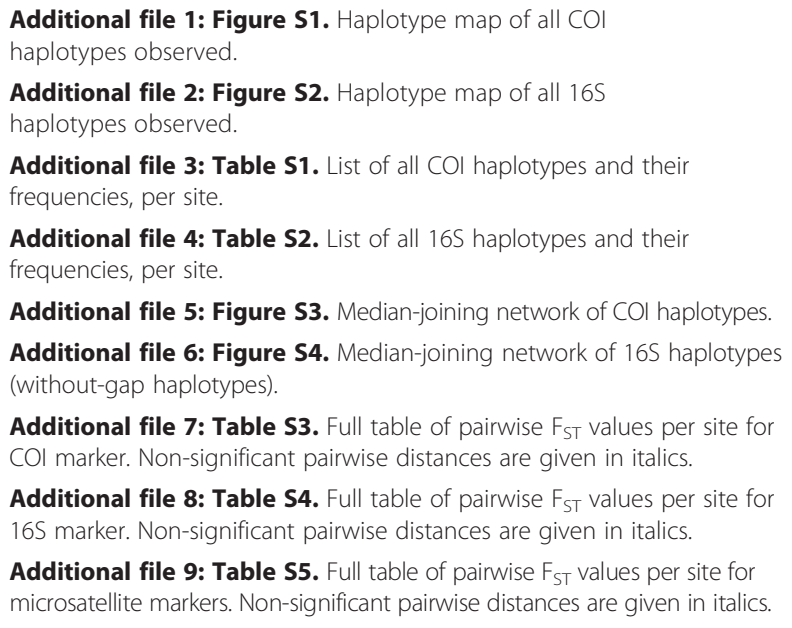

Additional file 3: Table S1. List of all COI haplotypes and their frequencies, per site.

Additional file 4: Table S2. List of all 165 haplotypes and their frequencies, per site.

Additional file 5: Figure S3. Median-joining network of $\mathrm{COI}$ haplotypes.

Additional file 6: Figure S4. Median-joining network of 165 haplotypes (without-gap haplotypes).

Additional file 7: Table S3. Full table of pairwise $F_{S T}$ values per site for COI marker. Non-significant pairwise distances are given in italics.

Additional file 8: Table S4. Full table of pairwise $F_{S T}$ values per site for 165 marker. Non-significant pairwise distances are given in italics.

Additional file 9: Table S5. Full table of pairwise $F_{S T}$ values per site for microsatellite markers. Non-significant pairwise distances are given in italics.

\section{Competing interests}

The authors declare they have no competing interests.

\section{Authors' contributions}

CJS conceived of the study, conducted the fieldwork, performed the experiments and analyses, and led the drafting of the manuscript. SLG assisted with analyses and the drafting of the manuscript. CMW assisted with analyses and the drafting of the manuscript. JRS assisting in conceiving the study, supervised the fieldwork, and assisted in analyses and drafting of the manuscript. All authors read and approved the final version of the manuscript.

\section{Acknowledgements}

The authors wish to thank the field teams from the Vector Control Division (Uganda), National Museums Kenya (Kenya) and the National Institute of Medical Research (Tanzania) for their assistance in the snail surveys and collections. We are also grateful to Dr Aslak Jørgensen, Dr Sylvester Nyakaana and Dr Allen Nalugwa for their field contributions. We thank the Commission for Science and Technology (COSTECH) in Tanzania, the Uganda National Council for Science and Technology (UNCST) and the Kenya National Council for Science and Technology (NCST) for permission to conduct this research.

\section{Financial support}

This work was funded by a Natural History Museum PhD studentship (CJS) and by the EU grant CONTRAST (CJS and JRS, FP6 STREP contract no: 032203, http://ec.europa.eu/research/health/infectious-diseases/neglecteddiseases/projects/035_en.html).

\section{Author details}

${ }^{1}$ School of Life Sciences, University of Nottingham, Nottingham NG7 2RD, UK ${ }^{2}$ Department of Zoology, Wolfson Wellcome Biomedical Laboratory, Natural History Museum, Cromwell Road, London SW7 5BD, UK. ${ }^{3}$ Department of Parasitology, Liverpool School of Tropical Medicine, Pembroke Place, Liverpool L3 5QA, UK. ${ }^{4}$ Present address: Milken Institute School of Public Health, George Washington University, Washington, D.C. 20052, USA.

Received: 18 July 2014 Accepted: 5 November 2014 Published online: 19 November 2014

\section{References}

1. Hoffman JI, Webster JP, Ndamba J, Woolhouse MEJ: Extensive genetic variation revealed in adjacent populations of the schistosome intermediate host Biomphalaria pfeifferi from a single river system. Ann Trop Med Parasitol 1998, 92:693-698.

2. Jarne $P$, Theron $A$ : Genetic structure in natural populations of flukes and snails: a practical approach and review. Parasitology 2001, 123:S27-S40.

3. Webster JP, Davies CM, Hoffman JI, Ndamba J, Noble LR, Woolhouse MEJ: Population genetics of the schistosome intermediate host Biomphalaria 
pfeifferi in the Zimbabwean highveld: implications for co-evolutionary theory. Ann Trop Med Parasitol 2001, 95:203-214.

4. Sandland GJ, Foster AV, Zavodna M, Minchella DJ: Interplay between host genetic variation and parasite transmission in the Biomphalaria glabrato Schistosoma mansoni system. Parasitol Res 2007, 101:1083-1089.

5. Sandland GJ, Wethington AR, Foster AV, Minchella DJ: Effects of host outcrossing on the interaction between an aquatic snail and its locally adapted parasite. Parasitol Res 2009, 105:555-561.

6. Webster JP, Woolhouse MEJ: Cost of resistance: relationship between reduced fertility and increased resistance in a snail-schistosome host-parasite system. Proc R Soc B Biol Sci 1999, 266:391-396.

7. Webster JP, Shrivastava J, Johnson PJ, Blair L: Is host-schistosome coevolution going anywhere? BMC Evol Biol 2007, 7:91. doi:10.1186/1471-2148-7-91.

8. Anderson RC: Nematode Parasites of Vertebrates: Their Development and Transmission. Volume 1. Wallingford, UK: CABl; 2000:672.

9. Esteban J-G, Muñoz-Antoli C, Trelis M, Toledo R: Biomphalaria Snails and Larval Trematodes. New York, NY: Springer New York; 2011:127-157.

10. Webster JP, Davies CM, Ndamba J, Noble LR, Jones CS, Woolhouse MEJ: Spatio-temporal genetic variability in the schistosome intermediate host Biomphalaria pfeifferi. Ann Trop Med Parasitol 2001, 95:515-527.

11. Charbonnel N, Angers B, Rasatavonjizay R, Bremond P, Debain C, Jarne P: The influence of mating system, demography, parasites and colonization on the population structure of Biomphalaria pfeifferi in Madagascar. Mol Ecol 2002, 11:2213-2228.

12. Mavárez J, Pointier JP, David P, Delay B, Jarne P: Genetic differentiation, dispersal and mating system in the schistosome-transmitting freshwater snail Biomphalaria glabrata. Heredity (Edinb) 2002, 89:258-265.

13. Lardans V, Dissous C: Snail Control Strategies for Reduction of Schistosomiasis Transmission. Parasitol Today 1998, 14:413-417.

14. Morgan JAT, Dejong RJ, Snyder SD, Mkoji GM, Loker ES: Schistosoma mansoni and Biomphalaria: past history and future trends. Parasitology 2001, 123:S211-S228

15. Brown D: Freshwater Snails of Africa and Their Medical Importance. 2nd edition. London: Taylor and Francis; 1994.

16. Stothard JR, Webster BL, Weber T, Nyakaana S, Webster JP, Kazibwe F, Kabatereine NB, Rollinson D: Molecular epidemiology of Schistosoma mansoni in Uganda: DNA barcoding reveals substantive genetic diversity within Lake Albert and Lake Victoria populations. Parasitology 2009, 136:1813-1824.

17. Stothard JR, Kabatereine NB, Tukahebwa EM, Kazibwe F, Mathieson W, Webster JP, Fenwick A: Field evaluation of the Meade Readiview handheld microscope for diagnosis of intestinal schistosomiasis in Ugandan school children. Am J Trop Med Hyg 2005, 73:949-955.

18. Standley CJ, Adriko M, Alinaitwe M, Kazibwe F, Kabatereine NB, Stothard JR: Intestinal schistosomiasis and soil-transmitted helminthiasis in Ugandan schoolchildren: a rapid mapping assessment. Geospat Health 2009, 4:39-53.

19. Standley CJ, Kabatereine NB, Lange C, Lwambo NJS, Stothard JR: Molecular epidemiology and phylogeography of Schistosoma mansoni around Lake Victoria. Parasitology 2010, 137:1937-1949.

20. Standley CJ, Wade C, Stothard JR: A fresh insight into the transmission of schistosomiasis: A misleading tale of Biomphalaria in Lake Victoria. PLoS One 2011, 6:e26563.

21. Asch HL: Rhythmic emergence of Schistosoma mansoni cercariae from Biomphalaria glabrata: Control by illumination. Exp Parasitol 1972, 31:350-355.

22. Stothard JR, Rollinson D: Partial DNA sequences from the mitochondrial cytochrome oxidase subunit I (COI) gene can differentiate the intermediate snail hosts Bulinus globosus and B. nasutus (Gastropoda: Planorbidae). J Nat Hist 1997, 31:727-737.

23. Folmer $\mathrm{O}$, Black $\mathrm{M}$, Hoeh $\mathrm{W}$, Lutz $\mathrm{R}$, Vrijenhoek R: DNA primers for amplification of mitochondrial cytochrome c oxidase subunit I from diverse metazoan invertebrates. Mol Mar Biol Biotechnol 1994, 3:294-299.

24. Bonnaud L, Boucher-Rodoni R, Monnerot M: Phylogeny of decapod cephalopods based on partial 16S rDNA nucleotide sequences. C R Acad Sci III 1994, 317:581-588.

25. Charbonnel N, Angers B, Razatavonjizay R, Bremond P, Jarne P: Microsatellite variation in the freshwater snail Biomphalaria pfeifferi. Mol Ecol 2000, 9:1006-1007.

26. Maddison DR, Maddison WP: MacClade 4: Analysis of phylogeny and character evolution. 2005, http://macclade.org/downloads/ReadMe.pdf.
27. Excoffier L, Laval G, Schneider S: Arlequin ver. 3.0: An integrated software package for population genetics data analysis. Evol Bioinform Online 2005, $1: 47-50$.

28. Swofford DL: PAUP*. Phylogenetic Analysis Using Parsimony (*and other methods). In Version 4. Sunderland, Massachusetts: Sinauer Associates; 2002.

29. Bandelt HJ, Forster P, Röhl A: Median-joining networks for inferring intraspecific phylogenies. Mol Biol Evol 1999, 16:37-48.

30. Raymond M, Rousset F: Genepop (Version-1.2) - Population-Genetics Software for Exact Tests and Ecumenicism. J Hered 1995, 86:248-249.

31. Cornuet JM, Luikart G: Description and power analysis of two tests for detecting recent population bottlenecks from allele frequency data. Genetics 1997, 144:2001-2014

32. Caldeira RL, Jannotti-Passos LK, Carvalho OS: Molecular epidemiology of Brazilian Biomphalaria: a review of the identification of species and the detection of infected snails. Acta Trop 2009, 111:1-6.

33. Born-Torrijos A, Poulin R, Raga JA, Holzer AS: Estimating trematode prevalence in snail hosts using a single-step duplex PCR: how badly does cercarial shedding underestimate infection rates? Parasit Vectors 2014, 7:243.

34. Ittiprasert W, Miller A, Su X, Mu J, Bhusudsawang G, Ukoskit K, Knight M: Identification and characterisation of functional expressed sequence tags-derived simple sequence repeat (eSSR) markers for genetic linkage mapping of Schistosoma mansoni juvenile resistance and susceptibility loci in Biomphalaria glabrata. Int J Parasitol 2013, 43:669-677.

35. Blouin MS, Bonner KM, Cooper B, Amarasinghe V, O'Donnell RP, Bayne CJ: Three genes involved in the oxidative burst are closely linked in the genome of the snail, Biomphalaria glabrata. Int J Parasitol 2013, 43:51-55.

36. Sire C, Durand P, Pointier JP, Theron A: Genetic diversity of Schistosoma mansoni within and among individual hosts (Rattus rattus): infrapopulation differentiation at microspatial scale. Int J Parasitol 2001, 31:1609-1616.

37. Dybdahl MF, Lively CM: The geography of coevolution: comparative population structures for a snail and its trematode parasite. Evolution (N Y) 1996, 50:2264-2275.

38. Bandoni SM, Mulvey M, Koech DK, Loker ES: Genetic structure of Kenyan populations of Biomphalaria pfeifferi (Gastropoda, Planorbidae). J Molluscan Stud 1990, 56:383-391.

39. Campbell G, Noble LR, Rollinson D, Southgate VR, Webster JP, Jones CS: Low genetic diversity in a snail intermediate host (Biomphalaria pfeifferi Krass, 1848) and schistosomiasis transmission in the Senegal River Basin. Mol Ecol 2010, 19:241-256

40. Davies CM, Webster JP, Kruger O, Munatsi A, Ndamba J, Woolhouse MEJ: Host-parasite population genetics: a cross-sectional comparison of Bulinus globosus and Schistosoma haematobium. Parasitology 1999, 119:295-302.

\section{doi:10.1186/s13071-014-0524-4}

Cite this article as: Standley et al.: The population genetic structure of Biomphalaria choanomphala in Lake Victoria, East Africa: implications for schistosomiasis transmission. Parasites \& Vectors 2014 7:524.

\section{Submit your next manuscript to BioMed Central and take full advantage of:}

- Convenient online submission

- Thorough peer review

- No space constraints or color figure charges

- Immediate publication on acceptance

- Inclusion in PubMed, CAS, Scopus and Google Scholar

- Research which is freely available for redistribution 